\title{
Electrochemical Characteristics of Carbonaceous Materials for Energy Storable Electrode Fabrication
}

\author{
Ki-Young Jung* ${ }^{\star}$ Doo-Hwan Kim $\cdot$ Youl-Moon Sung ${ }^{\star *}$
}

\begin{abstract}
Photo-capacitor electrodes are attracting great attention because of their high capacitance and potential applications in electronic devices. Carbon capacitor, active carbon capacitor and its combination will be fabricated using a sandwich method as carbonaceous material on each type of storable electrode with $20 \times 15[\mathrm{~mm}]$ cell size. Carbon/active carbon cell was fabricated using sol-gel process with $120\left[{ }^{\circ} \mathrm{C}\right]$ dry temperature in 2hour and using sintering process with $500\left[{ }^{\circ} \mathrm{C}\right]$ in 2 hour.

The effect of sintering temperature on carbon properties was also investigated with an $\mathrm{X}$-ray diffraction technique to get the best sintering temperature. The detail of the fabrication process will be explained. Active carbon as carbonaceous material has a better capacitance in storable electrode with mean thickness $32[\mu \mathrm{m}]$ and with particle size $1[\mu \mathrm{m}]$ to $4.5[\mu \mathrm{m}]$ in $20 \times 15[\mathrm{~mm}]$ sample size of storable electrode.
\end{abstract}

Key Words : Photocapacitor, Sol-Gel Process, Carbonaceous Material, Capacitor, Active Carbon

\section{Introduction}

Photovoltaic power generation[1,2] is a useful technique for the prevention of global warming and energy problems. However, the generation power is strongly influenced by the weather, and therefore the stable supply of the electric power is difficult to attain. To use solar energy efficiently, a storage battery that can deliver the stable electric power to

* Main author : Kyungsung University

** Corresponding author: Kyungsung University

Tel : +82-51-663-4777, Fax : +82-51-624-5980

E-mail : ymsung@ks.ac.kr

Date of submit:2009. 10. 27

First assessment : 2009. 10. 29, Second : 2010. 7. 12

Completion of assessment : 2010. 7. 23 the load is required. Electrochemical capacitors using carbonaceous materials as the main component in the electrode construction are next generation capacitors which are commercialized in full scale[3]. They are complementary to batteries as they deliver high power density and low energy density. They also have longer cycle life than batteries and possess higher energy density as compared to conventional capacitors.

This has led to new concepts of the so-called hybrid charge storage devices in which electrochemical capacitor is interfaced with a fuel cell, a solar cell ced battery. These capacitors are commercialized and used with active carbon as the main electrode material for both anode and cathode 
with solid/liquid electrolytes. Many researchers try to improve the performance of these electrochemical capacitors by modifying the electrode construction or materials[4-10]. Recently, Miyasaka et al[11,12] have reported Grätzel-celltype photocapacitors. The device is generally composed of a glass substrate/dye- ${ }^{-}$sensitized $\mathrm{TiO} 2$ porous layer/activated carbon layer/electrolyte/activated carbon layer/ cathode electrode. The photo-generated charges are stored at the electrochemical capacitor using two symmetrical electrodes with active carbon materials. However, the power conversion efficiency of the photocapacitor is far lower than the level of existing photovoltaic cells. More study is still required regarding efficiency, long-term stability and cost-effectiveness.

In this work, the electrochemical characteristics of the Grätzel cell type capacitors based on nanoporous carbonaceous electrode prepared by sol-gel and screen printing methods were investigated. The charge- ${ }^{-}$voltage characteristics of the photocapacitors connected to Grätzel-cell were evaluated. Based on the observed electrochemical properties, the relationships between the properties of carbonaceous electrode materials and the performance of electrochemical capacitors were addressed.

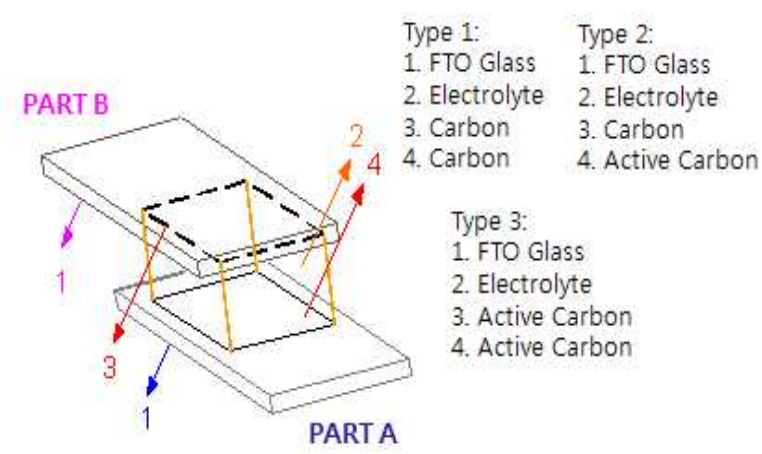

Fig. 1. Photo-capacitor electrode illustration

\section{Experimental}

Carbonaceous materials were assembled to conducts glass made with simple sandwich type. Storable electrode was fabricated using simple sandwich method and made in three different varieties. This fabrication method is shown in Fig.1.

Carbon and active carbon paste was used in this material as a cell which size $20 \times 15[\mathrm{~mm}]$. Capacitor is separated in two parts and electrolyte is used as a separator. Firstly, paste was made by using sol-gel combustion method. Carbon/active carbon owder was immersed in 15[ml] Titanium Iso-propoxide and 100[me] 2-propanol for 1 hour, mixed by using magnetic stirrer. In this process, Carbon/active carbon powder of $0.4[\mathrm{~g}]$ was added to this solution and $10 \sim 15[\mathrm{ml}] \mathrm{NH}_{4} \mathrm{OH}+\mathrm{H}_{2} \mathrm{O}(1: 1)$ was added drop by drop under constant stirring until it turned to a sol at ambient condition. Then, in sol condition, carbon or active carbon was heated at $120\left[{ }^{\circ} \mathrm{C}\right]$ in 2 hour to make a dried gel to perform sintering process. Sintering process is needed to obtain a very high purity of carbon/active carbon. Sintering temperature in carbon will analyzed with $450\left[{ }^{\circ} \mathrm{C}\right] \sim 520\left[{ }^{\circ} \mathrm{C}\right]$ in 2 hour and it shown in Tablel. Particle sizes of carbon and active carbon were investigated by field emission scanning electron microscope. In 1 gram dry carbon, 2[m $]$ a-terpineol with 0.7 gram ethyl cellulose was immersed in 100 [ml] Ethanol for 1 hour and put in ultrasonic cleaning. Then, using evaporation process, carbon/active carbon paste can be made in 8 10 min with $50\left[{ }^{\circ} \mathrm{C}\right] \sim 75\left[{ }^{\circ} \mathrm{C}\right]$ in water heated chamber. The carbon paste, used for comparison, was prepared in exactly the same manner as that of the active carbon. Carbonaceous materials as carbon and active carbon paste cell were assembled using the same method and prepared using screen printing method. The cells were doctor bladed onto 
conducting glass plates using a glass rod or a rod coater. The method is illustrated in Fig. 2.

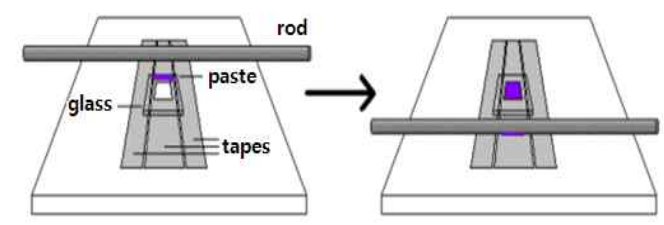

Fig. 2. Carbonaceous materials Assembly

A cast frame was cut out of tape (Removable Magic Tape) and it was laid over the glass substrate. Mold was made from rectangular aluminum pipe to achieve some consistency in the carbonaceous area. The edges of the aluminum pipe could not been made sharp enough. A pattern size of the cast (cell) was cut using a scalpel on a cardboard and the tapes were then laid on the cardboard and cut using the pre-cut pattern. Additiona noapes were required to cover the sides of the glass ot brevent the paste from ss cuing the 25 xe $\mathrm{p}$ [mm] sized glass to ste was initially dispensed using a small spoon and aluminum pipe as a rod coater. When using the rod coater, the spt and pressure of the rod on the glass can be controlled. Due to the a scaviscoal onand scowspening of the paste, it can be appl cousevera noimes until satisfactory quality of the cells is reached. After the paste was spread, conducting glass was left to dry for 5 minutes before the tapes were removed and then it left to dry at $70\left[{ }^{\circ} \mathrm{C}\right]$ for 10 minutes.

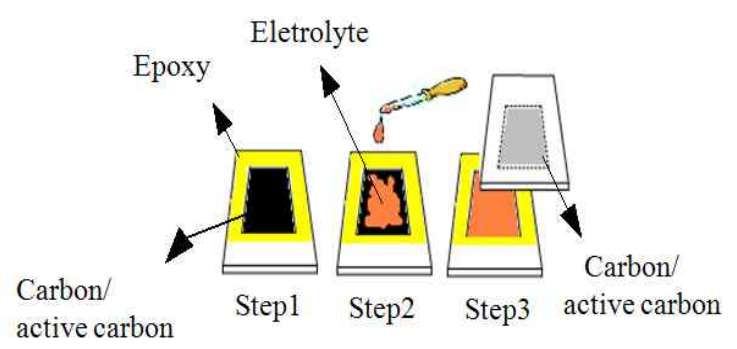

Fig. 3. Capacitor assembly process
A storable electrode was made using two electrodes with carbon and active carbon. Two electrode capacitors were made in the same way which carbon and active carbon was made as a cell. This process is shown in fig. 3. Storable electrode which prepared using three different varieties was prepared using the same way for each capacitor. The electrode were placed a little off-center to accommodate the electrical contacts. In one side of electrode, fast epoxy glue was covered in around cell and must be waited until 3 minutes before two electrodes will be attached together. Electrolyte contains $5[\mathrm{ml}]$ Acetonitrile, $50[\mathrm{mM}] \mathrm{I}_{2}, 580[\mathrm{mM}]$ tert-butylpyridine, and $500[\mathrm{mM}]$ lithiumiodide. The function of the sealing is to prevent the electrolyte from leaving the cell. But it also keeps moisture from entering the cell as water can have a degrading effect in the cell components.

\section{Results and discussion}

The structural and physical characterization of storable electrode was characterized by alpha step, $\mathrm{X}$-ray diffraction techniques (XRD), and $\mathrm{X}$-ray photoelectron spectroscopy (XPS). Elemental composition in carbonaceous material can be measured using quantitative spectroscopic as $\mathrm{X}$-ray photoelectron spectroscopy (XPS).

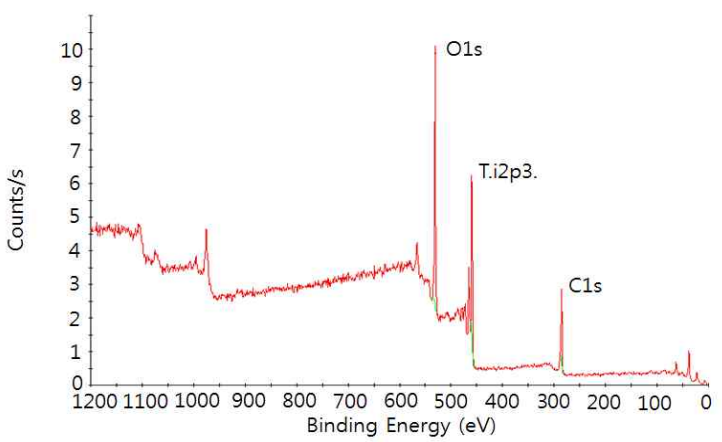

Fig. 4. X-ray photoelectron spectroscopy(XPS) of active carbon electrode 
In this work, elemental composition of carbon and active carbon powder was investigated and can be seen in fig. 4. Further inspection of XPS spectra provides additional information concerning the catalyst's structure. The observed signal result from two main contributions (carbon and active carbon), distinguish three peaks. Photoelectron peaks for $\mathrm{O}$ 1s, Ti 2p3 and C 1s were detected for the storable capacitor in the binding energy range 0 to $1200[\mathrm{eV}]$. In carbon, the binding of the $\mathrm{O}$ 1s photoelectron peak is at $536.6[\mathrm{eV}]$ and usually attributed to oxygen bonded to the carbon. O 1s signal and is strongly attenuated. The $\mathrm{C} 1 \mathrm{~s}$ spectra are characterized by a main peak at $291.7[\mathrm{eV}]$ attributed to graphitic carbon and a smaller shoulder at 536.6[eV] assigned to $\mathrm{C}-\mathrm{O}$ functional groups. The oxygen is bonded to the carbon and TI. The binding energy of $\mathrm{Ti} 2 \mathrm{p} 3$ is $462.3[\mathrm{eV}]$. Using the same analysis, in active carbon, $\mathrm{O} 1 \mathrm{~s}$, Ti $2 \mathrm{p} 3$ and $\mathrm{C} 1 \mathrm{~s}$ were detected for the storable, using the same binding energy. The binding energy of the $\mathrm{C} 1 \mathrm{~s}$ photoelectron peak is at 292.75[eV]. The oxygen bonded in active carbon at $536.25[\mathrm{eV}]$ and the binding energy of Ti $2 \mathrm{p} 3$ is the same with carbon which the peaks reach at $462.3[\mathrm{eV}]$.

Active carbon is used to know the carbon cell thickness which 4 carbon sample were analyzed with mean thickness 32[um]. Active carbon paste must have the same thickness with carbon because it used for comparison (thickness range 30 40[ $\mu$ $\mathrm{m}]$ ). High purity of carbon has become important for research to get the best sample. Carbon powder with $500\left[{ }^{\circ} \mathrm{C}\right]$ sintering temperature in 2 hour is the better temperature to get the high purity of carbon and the better efficiency in discharge process.

Figure 5 shows a sample for XRD patterns of active carbon electrode at the condition of sintering temperature of $450\left[{ }^{\circ} \mathrm{C}\right]$. The $\mathrm{XRD}$ patterns of carbon

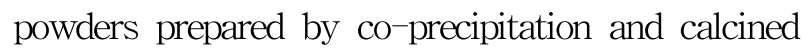

at $450\left[{ }^{\circ} \mathrm{C}\right] \sim 520\left[{ }^{\circ} \mathrm{C}\right]$.

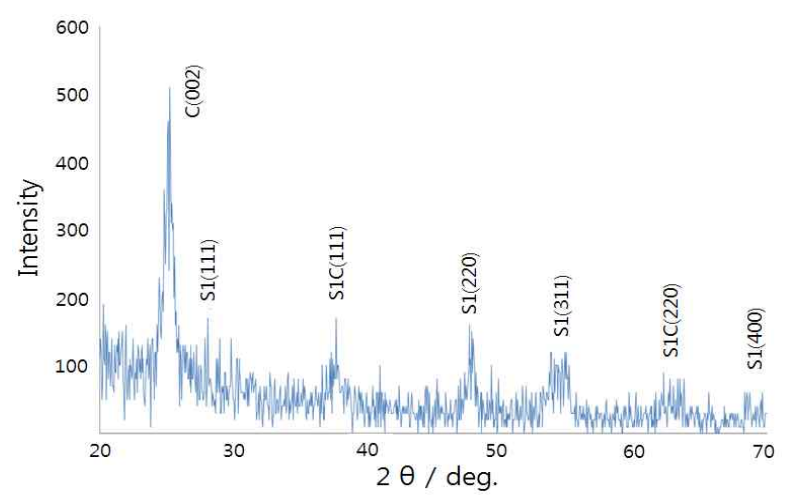

Fig. 5. XRD pattern of carbon at the condition of $450\left[{ }^{\circ} \mathrm{C}\right]$ sintering temperature

Table. 1. Carbon paste manufactures condition

\begin{tabular}{|l|c|c|c|c|}
\hline \multicolumn{1}{|c|}{ Carbon } & $\mathrm{A}$ & $\mathrm{B}$ & $\mathrm{C}$ & $\mathrm{D}$ \\
\hline Dry temperature & $120\left[{ }^{\circ} \mathrm{C}\right]$ & $120\left[{ }^{\circ} \mathrm{C}\right]$ & $120\left[{ }^{\circ} \mathrm{C}\right]$ & $120\left[{ }^{\circ} \mathrm{C}\right]$ \\
\hline Time & $120[\mathrm{~min}]$ & $120[\mathrm{~min}]$ & $120[\mathrm{~min}]$ & $120[\mathrm{~min}]$ \\
\hline Sintering temperature & $450\left[{ }^{\circ} \mathrm{C}\right]$ & $480\left[{ }^{\circ} \mathrm{C}\right]$ & $500\left[{ }^{\circ} \mathrm{C}\right]$ & $520\left[{ }^{\circ} \mathrm{C}\right]$ \\
\hline Time & $120[\mathrm{~min}]$ & $120[\mathrm{~min}]$ & $120[\mathrm{~min}]$ & $120[\mathrm{~min}]$ \\
\hline
\end{tabular}

In Table 1, the different sintering temperature were analyzed to know the best capacity in storable electrode. From the result, carbon powder at $500\left[{ }^{\circ} \mathrm{C}\right]$ showed very sharp diffraction peaks and very broad diffraction lone, indicating good crystalline. It showed better developed diffraction reflections of various carbons through the different sintering temperature. Carbons in general show a 002 diffraction maxima at $2 \Theta-25\left[^{\circ}\right]$ and overlapped 100 and 101 maxima (usually identified as the 10 peak) at $2 \Theta-42\left[^{\circ}\right]$. The stack height $\mathrm{Lc}$, of the graphitic micro-crystallites is determined by the width of the 002 peak. Carbon heated found that both diffraction peaks near 25 and $42\left[^{\circ}\right]$ grow with the increase of heating temperature.

They also proposed a geometric relationship between the microcrystalline structures and specific surface area of carbon. The size, mutual orientation 
and stacking of the micro-crystallites are intimately associated with the micro-porosity and the high surface area. A small crystallite thickness and short range ordering between crystallites is necessary for the realization of super high surface area activated carbons.

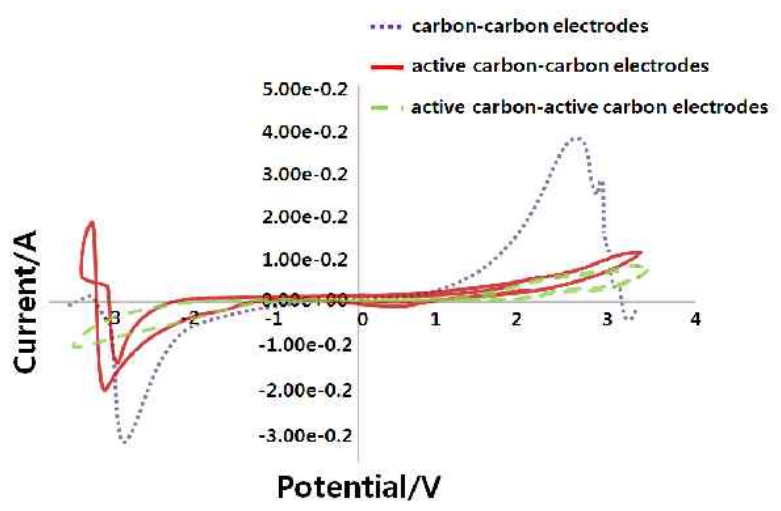

Fig. 6. Cyclic voltammograms characterist ics of active carbon electrode

Cyclic voltammetry appeared as different carbonaceous material was used to determine the electrochemical properties of electrode capacitor and thus to quantify the specific capacitance for each capacitor. Fig. 6 shows the sample for cyclic voltammetry of active carbon as electrode for electrode capacitor. The electrode potential was scanned between -3.5 and $3.5[\mathrm{~V}]$ at $50[\mathrm{mV} / \mathrm{s}]$ with different carbonaceous material. The voltammogram shows a resolved peak at $2.7[\mathrm{~V}]$ and $-2.8[\mathrm{~V}]$ in carbon- ${ }^{-}$arbon carbonaceous material, $3.4[\mathrm{~V}]$ and $-3.2[\mathrm{~V}]$ in active carbon-carbon material and 3.5[V] and $-3.5[\mathrm{~V}]$. It can be seen that the two traces are almost similar. There is a drop in current peak between the electrodes from $3.2 \times 10^{-2}$ to $3.7 \times 10^{-2}$ for carbon material, from $1.3 \times 10^{-2}$ to $6.9 \times 10^{-2}$ for active carbon-carbon material and from $9.9 \times 10^{-2}$ to $8.8 \times 10^{-2}$ for active carbon material which increasing as the potential goes past the critical limit. In $\mathrm{c}^{-} \mathrm{v}$ characteristic, active carbon is more constant on the surface of the electrode than the other carbonaceous material which detaches from the electrode and allows the current to increase as a function of increased potential.

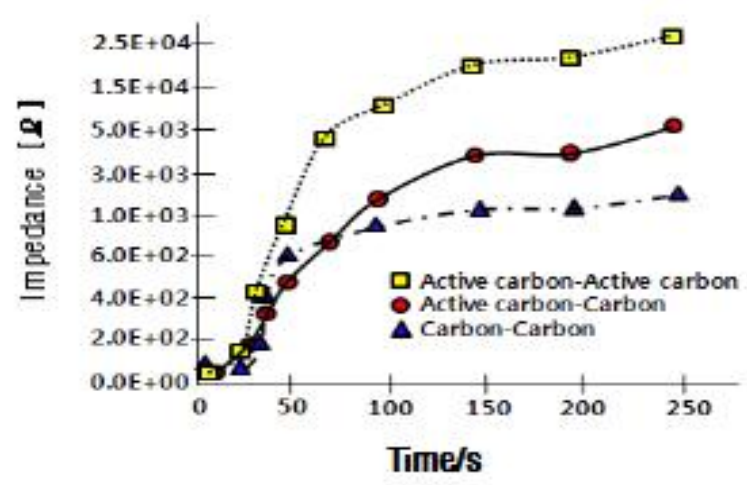

Fig. 7. Impedance characteristics of active carbon electrode

Impedance characteristic processes are assumed to determine the capacitor charging time and each carbonaceous material can be compared. The impedance result is determined from the combination of the device capacitance, the resistances of the electrolyte, and carbonaceous material itself.

Given an electrode area, thickness, capacitance per unit volume, and spacing between electrodes effect the impedance characteristic. Fig. 7 shows the impedance characteristic of active carbon electrode. An estimate of the time dependence of impedance, mass transport in the capacitor faster in range frequency value $20[\mathrm{kHz}]$ (50 s times constant). Active carbon material has higher impedance than the other electrode. On time scales where mass transport within the electrode limits, charging the apparent volumetric capacitance will be lower than the capacitance observed at longer time. In cases where impedance is dominant, mass transport limits are estimated using a model in which capacitance is allowed to vary with frequency. 


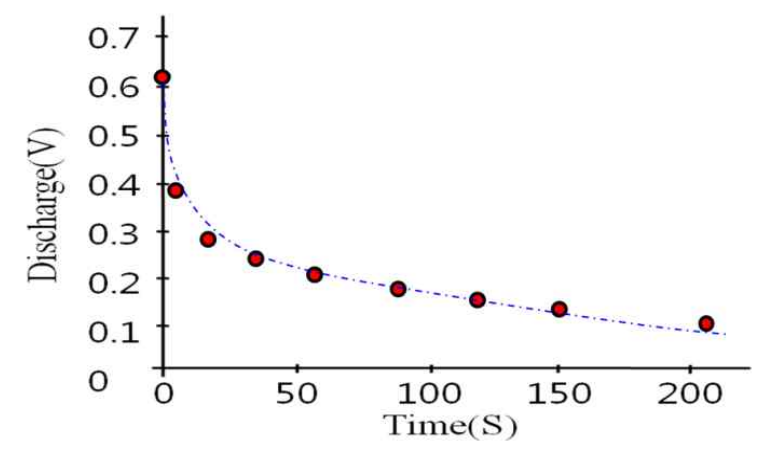

Fig. 8. Discharging characteristic in storable electrode application

Storable electrode carbonaceous materials for photo-capacitor application are initiated by the light-induced charge separation of dye molecules at the hetero-junction interface and the electron injection from photo-excited dye molecules to the semiconductor conduction band following the mechanism of dye sensitization. Electron and holes of dye transfer to electrode capacitor which positive and negative charges will be accumulated on the microporous surface of carbon or active carbon. Fig. 8 exhibits storable electrode behavior application in the discharge process and voltage decrease in the discharge process which a main component as Grätzel-cell was eliminated. The voltage approximately decreases in constant condition.

\section{Conclusions}

Storable electrode fabrication using a simple sandwich method works well with $20 \times 15[\mathrm{~mm}]$ size carbonaceous material. Three different samples were analyzed. Carbonaceous materials using active carbon in both parts of the sandwich method have higher impedance than the other carbonaceous material in the sample. An estimate of the time dependence of impedance, showed mass transport in the capacitor faster in range frequency value $20[\mathrm{kHz}](50 \mathrm{~s}$ times constant). This-experiment demonstrated that a simple sandwich capacitor 500 $\left[{ }^{\circ} \mathrm{C}\right]$ sintering temperature in two hours has the highest purity of carbon and it is the most efficient in a discharge process that uses the sol-gel method with mean thickness in each type of capacitor that is $32[\mu \mathrm{m}]$.

\section{References}

[1] B. O. Regan, M. Gratzel, "A low cost, high-efficiency solar cell based on dye-sensitized colloidal $\mathrm{TiO}_{2}$ films", Nature, vol.353, pp. 737-740, October 1991.

[2] M. Gra"tzel, "Photoelectrochemical cells", Nature, vol.414, pp.338-344, 2001

[3] M Jayalakshmi, K Balasubramanian, "Simple Capacitors to Supercapacitors - An Overview," Int. J. Electrochem. Sci, vol.3, pp.1196 - 1217, 2008.

[4] A. Gamard, G. Campet, B. Jousseaume, T. Toupance, New Fluorinated Stannic, "Compounds as Precursors of F-Doped $\mathrm{SnO}_{2}$ Materials Prepared by the Sol-Gel Route", Chem, vol.38, pp.4671, 1999.

[5] A. G. Pandolfo, A. F. Hollenkamp, "carbon properties and their role in supercapacitors", J. Power Sources, vol.157, pp.11, 2006.

[6] M. Jayalakshmi, M. Mohan Rao, N. Venugopal, Kwang-Bum Kim, "Hydrothermal synthesis of $\mathrm{SnO}_{2}-\mathrm{V}_{2} \mathrm{O}_{5}$ mixed oxide and electrochemical screening of carbon nano-tubes (CNT), $\quad \mathrm{V}_{2} \mathrm{O}_{5}, \quad \mathrm{~V}_{2} \mathrm{O}_{5}-\mathrm{CNT}, \quad$ and $\quad \mathrm{SnO}_{2}-\mathrm{V}_{2} \mathrm{O}_{5}-\mathrm{CNT}$ electrodes for supercapacitor applications", J. Power Sources, vol. 166, pp.578, 2007.

[7] E. Raymundo-Piñero, K. Kierzek, J. Machnikowski, F. Béguin, Carbon, "Relationship between the nanoporous texture of activated carbons and their capacitance properties in different electrolytes ", vol.44, pp.2498, 2006.

[8] H. Liu, G. Zhu, "Hollow Inorganic Nanospheres and Nanotubes with Tunable Wall Thicknesses by Atomic Layer Deposition on Self-Assembled Polymeric Templates", J. Power Sources, vol.171, pp.1054, 2007.

[9] D. Tashima, K. Kurosawatsu, M. Uota, T. Karashima, M. Otsubo, C. Honda, Y. M. Sung, "Space charge distributions of an electric double layer capacitor with carbon nanotubes electrode", Thin Solid Films, vol.515, pp.4234, 2007.

[10] M. Kemell, M. Ritala, M. Leskelä, E. Ossei-Wusu, J.Carstensen, H. Föll, Microelectron."Si/Al2O3/ZnO:Al capacitor arrays formed in electrochemically etched porous $\mathrm{Si}$ by atomic layer deposition”, Eng. vol.84, pp.313-318, 2007.

[11] T. Miyasaka, T. N. Murakami, "An efficient self-charging capacitor for direct storage of solar energy", vol.85, pp.3932, 2004. 
[12] Tsutomu Miyasaka and Takurou N. Murakami, "The photocapacitor: An efficient self-charging capacitor for direct storage of solar energy", Applied Physics Letters, Vol.85, pp.3932-3933, 2004.

\section{Biography}

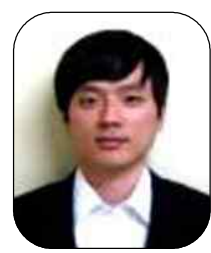

\section{$\mathrm{Ki}-$ Young Jung}

He was born in korea in 1983. He graduated, in 2009, $\mathrm{Ki}^{-}$-young Jung from Kyungsung University ,Busan, South Korea. Presently he is on a master's course at Kyungsung University, Busan, South Korea. His research interest is renewable energy and plasma applications.

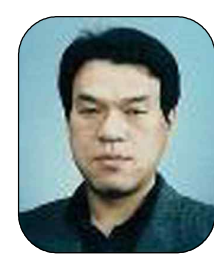

\section{Doo-Hwan Kim}

He was born in Korea in 1961. He graduated in 1988 from Pusan National University, Busan, Korea, where he received his M.S. and Ph.D. degrees in 1989 and 1997, respectively. He was an assistant professor from 1998 to 2002 at Nam Hae College. He was a research team Pulsetec. Presently he is special researcher at Kyungsung University, Busan, South Korea. His research interest is renewable energy and plasma applications.

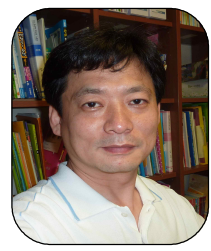

Youl-Moon Sung

He was born in Korea in 1966. He graduated in 1992 from Pusan National University, Busan, Korea, where he received his M.S. and Ph.D. degrees, in 1994 and 1996, respectively. He undertook a postdoctoral position from 1997 to 1998 at Kyushu University, Fukuoka, Japan. He became a Research Associate and an Associate Professor at Kyushu University in 1999 and at the University of Miyazaki, Miyazaki, Japan, in 2004, respectively. Presently he is a professor at Kyungsung University, Busan, Korea. His research interest is energy materials and application. 